\title{
A Juventude brasileira e a educação: Um estudo acerca da garantia à educação como preparação para o trabalho
}

\author{
Brazilian youth and professional education: a study \\ about the guarantee to education as a preparation for \\ work
}

Adriana Aparecida de Souza 5

\section{Resumo}

Propõe-se, nesta pesquisa, desenvolver um estudo exploratório acerca dos jovens brasileiros em articulação com a educação profissional com vistas a compreender como o Estado brasileiro atende o direito à educação e ao trabalho. Parte-se dos seguintes questionamentos: Sendo a educação e o trabalho direitos constitucionais, como o Estado brasileiro vem atendendo esses direitos em relação aos jovens de 15 a 29? A educação profissional tem alcançado os jovens das camadas populares? Como vem ocorrendo esse atendimento no século XXI? O que indicam os dados oficiais sobre essas questões? Reconhece-se que o Estatuto da Juventude, instituído pela Lei $n^{\circ}$ 12.852/2013, entende jovens com idade entre 15 e 29 anos, neste documento também dispõe quais são os direitos dos jovens informando as garantias já previstas pela Constituição, quais são as especificidades da juventude que precisam ser afirmadas. Contudo, observa-se que as políticas públicas não têm atendido às demandas dos jovens por Educação profissional. Como metodologia adota-se uma abordagem materialista-dialética no sentido de análise da realidade por meio de: pesquisa bibliográfica acerca dos fundamentos da Educação profissional oferecida no Brasil, e análise de instrumentos jurídicos/legais tais como: o texto Constitucional atual, o Estatuto da Criança e do Adolescente, a Lei de Diretrizes e Bases da Educação, e as Consolidações das Leis do Trabalho, na busca de evidenciar os marcos legais das principais políticas públicas voltadas à garantia dos direitos à

5 Programa de Pós-Graduação Profissional em Educação Profissional do Instituto Federal de Educação, Ciência e Tecnologia do Rio Grande do Norte (Pós-Doutoranda); ORCID: https://orcid.org/0000-0001-69331121. E-mail: drycacyda@yahoo.com.br. 
educação e ao trabalho. Além disso, abordaremos a análise dos indicadores oficiais sobre Educação profissional nas bases de dados do Estado brasileiro em domínio público, para subsidiar a exposição com argumentos da realidade estudada. Trata-se, portanto, de um estudo quali-quantitativo de base legal com fundamentos histórico-críticos que se alicerçará em indicadores que mostrarão a garantia ou não da educação como preparação para o trabalho.

Palavras-chave: Educação Profissional. Juventude. Políticas Públicas. LDB.

\begin{abstract}
It is proposed, in this research, to develop an exploratory study about Brazilian young people in articulation with professional education with the goal to understanding how the Brazilian State fulfills the right to education and work. It begins with the following questions: Since education and work are constitutional rights, how the Brazilian State is attending these rights in relation to young people from 15 to 29 years old? Has professional education reached young people from the popular layers? How has this service been happening in the 21st century? What do official data indicate about these issues? It is recognized that the Youth Statute, established by Law no. 12.852/2013, covers young people aged between 15 and 29 years old, this document also sets what are the rights of young people by informing them about the guarantees already provided for in the Constitution, what are the specificities of youth that need to be affirmed. However, it can be observed that public policies have not met the demands of young people for professional education. As a methodology, it is adopted a materialistic-dialectical approach in the sense of analyzing reality through: bibliographic research about the foundations of Professional Education offered in Brazil, analysis of legal instruments such as: the current constitutional text, the Adolescent and child statute, the Law of Guidelines and Bases of Education, the Consolidation of Labor Laws, in an attempt to highlight the legal frameworks of the main public policies aimed at guaranteeing the rights to education and work, as well as the analysis of the official indicators on Professional Education in the databases of the Brazilian State in the public domain, to subsidize the exposition with arguments of the studied reality. It is, therefore, a qualitative and quantitative study with a legal basis with historical-critical foundations that will be based on indicators that will show the guarantee or not of education as preparation for work.
\end{abstract}

Keywords: Professional Education. Youth. Public policies. LDB. 


\section{Introdução}

Este estudo vem sendo desenvolvido no sentido de aprofundar algumas questões provenientes de reflexões sobre o Trabalho e a educação no Brasil como direitos constitucionais. Assim, seguindo essa premissa compreende-se que devem ser respeitados e garantidos pelo Estado e por seus representantes, independente de qualquer governo que esteja no poder.

Sendo assim, refletir sobre Educação Profissional traz em sua essência os sujeitos que poderiam ser os beneficiários dessa educação - os jovens da classe trabalhadora. A garantia dos direitos à educação e ao trabalho pelo Estado brasileiro seria um meio deste respeitar e cumprir a responsabilidade de efetivação desse direito, mas isso tem sido um desafio que parece inalcançável. Todavia, se tornou objeto de estudos por intelectuais como: Frigotto (2001); Moura (2008); Trevisan e Belen (2008); Secchi (2011) entre outros.

O texto constitucional relaciona profissionalização e educação com o desenvolvimento da pessoa humana, em toda sua potencialidade. O objetivo da profissionalização é, portanto, educacional, posto que além da sua especificidade, soma-se a essa outros valores que se sobrepõem ao mundo da educação pelo trabalho como garantia de bem-estar social dos sujeitos, direcionando-se sua finalidade para o exercício pleno da cidadania.

Os Arts. 39 a 42 da Lei n 9.394/1996 da Lei de Diretrizes e Bases da Educação (LDB) especificam que a Educação Profissional deverá tornar o indivíduo apto para a vida produtiva, ou seja, a escola fornece conhecimentos que tenham alguma utilidade para que 0 aluno possa engajar-se profissionalmente e participar da sociedade. A LDB incorpora, assim, o trabalho de forma restrita e universal, sendo, desse modo, meio de incentivo à integração da escola à comunidade e à vida social.

Em referência à Educação Profissional, ou preparo para o trabalho, a LDB, mostra que a função da escola é preparar os alunos com conhecimentos básicos sobre as profissões e sobre as perspectivas para o ingresso no mercado de trabalho. Contudo, os problemas da política de formação e qualificação 
profissional se apresentam em indicadores educacionais do próprio governo federal de forma aquém das demandas da sociedade, notadamente da população jovem que carece dessa formação como modo de garantia de sua subsistência. Assim, por si mesmo o Estado se declara como ineficiente no que tange à garantia desse direito.

Reconhece-se que o mundo do trabalho vem sofrendo os reflexos dessas contradições dos sistemas educacionais no Brasil, mais acentuadamente quando trata da atenção dos jovens que estão à procura de emprego, de trabalho para sua subsistência e, muitas vezes, para a da família. Ressalte-se que em um país capitalista a ideia é atender ao sistema pela produtividade e o lucro. Isso significa que os trabalhadores devem adequar-se prioritariamente às necessidades do mercado, atendendo à lógica produtivista e acumulativa do capital, baseada na exploração da força de trabalho com pouca qualificação.

O Estatuto da Juventude, instituido pela Lei n. ${ }^{0}$ 12.852/2013, determinou quais são os direitos dos jovens, informando as garantias e como devem ser promovidos pelo Estado brasileiro, estabelecendo ainda, dentre as garantias já previstas pela Constituição, quais são as especificidades da juventude que precisam ser afirmadas. Todavia, observa-se que as políticas públicas não têm atendido às demandas dos jovens por educação profissional. Observa-se também que algumas que parecem ser demanda social, são demandas geradas pela própria organização da educação, cite-se o caso da oferta de Educação Profissional como subsequente ao Ensino Médio. Essa oferta ratifica a "inclusão excludente" (KUENZER, 2006), pois os filhos da classe trabalhadora retornam para a escola, não para mudar de nível de escolarização, mas para permanecer onde estavam.

Sendo assim, não basta que os direitos à educação e ao trabalho estejam declarados na Carta Magna, em legislações complementares e em legislações regulamentadoras de políticas educacionais afins se não forem garantidos pelo Estado por ações políticas concretas.

A Educação Profissional integrada ao Ensino Médio deveria ter como finalidade formar cidadãos para ingressarem no mundo e no mercado de 
trabalho, garantindo assim, o direito à educação - o direito ao trabalho. No entanto, há de se analisar ao longo desta pesquisa se as políticas educacionais para educação profissional, direcionadas aos jovens no Brasil são capazes de abranger uma parcela verdadeiramente significativa da sociedade, para verificar quais as diretrizes e orientações possiveis para aumentar e atingir uma parcela ainda maior de cidadãos educandos de 14 a 29 anos no Brasil. Isso porque, observa-se que em termos legais há legislações especificas que já garantem esses direitos, e essas, já se encontram devidamente regulamentadas.

É necessário pontuar a utilização do termo "juventude" em nossa pesquisa, pois reflete sobre documentos legais entre eles o Estatuto da Juventude, instituido pela Lei $n^{\circ} 12.852 / 2013$, que entende jovem em termos legais entre os 15 aos 29 anos de idade, bem como, a educação profissional e dentro desse contexto, procura-se conexões que nos ajudem a compreender os meandros do acesso à educação profissional e a inclusão no mundo do trabalho para a juventude.

Diante do que se apresenta no contexto do século XXI, para a condução dessa pesquisa parte-se do seguinte questionamento: Sendo a educação e o trabalho direitos constitucionais, como o Estado brasileiro vem atendendo esses direitos em relação aos jovens de 15 a 18 anos? A Educação Profissional tem alcançado os jovens das camadas populares? Como vem ocorrendo esse atendimento no século XXI? O que indicam os dados educacionais oficiais sobre essas questões? Estes questionamentos nos impeliram a dar continuidade ao estudo, que ora apresentamos, o qual é parte integrante do Programa Nacional de Pós-Doutorado (PNPD), associado ao Programa de Pós Graduação em Educação Profissional (PPGEP) do Instituto Federal de Educação, Ciência e Tecnologia do Rio Grande do Norte (IFRN), sob a orientação do Professor Dante Henrique Moura. Objetivou-se nesta pesquisa, desenvolver um estudo exploratório acerca dos jovens brasileiros em articulação com a Educação Profissional com vistas a compreender como o Estado brasileiro atende o direito à educação e ao trabalho para estes jovens. 
Inicialmente discute-se sobre a temática nas teorias sobre educação profissional no contexto das políticas públicas de educação, que nos dão elementos para a discussão do problema, servindo como argumento para a sustentação de nossa proposta de pós-doutorado, qual seja, a apreensão das ações do Estado na construção da cidadania dos jovens.

\section{Breve história da construção da educação como direito fundamental das políticas de acesso à educação}

Entende-se que o conceito de juventude é polissêmico, interdisciplinar, pois envolve todo um contexto histórico social e cultural da experiência humana. E desse modo, uma parte importante do processo de construção da identidade dos sujeitos em sua individualidade e também em coletividade, bem como, todo um conjunto geracional estabelecido no contexto nas sociedades. (BOURDIEU, 1983; DARYELL, 2003; BELLUZZO, VICTORINO, 2004).

Assim, entende-se por juventude uma etapa do ciclo da vida na qual culmina o processo de socialização dos sujeitos, pois prepara o indivíduo para a produção e reprodução da vida em sociedade (ABRAMO, 2005). Tal concepção tem influência muito forte nas sociedades ocidentais, erigida sobre pilares capitalistas em que a entrada no mundo do trabalho/emprego é questão fundamental para o projeto de vida. Esse aspecto apresenta uma relação circular de fortalecimento mútuo com as políticas públicas, especialmente as de educação, trabalho e de renda.

Nesse contexto a sociedade brasileira enfrenta na atualidade uma crise na forma de educar e compreender a relação entre formação/educação no processo de socialização de instituições sociais como a família e a escola. Acredita-se que é necessário a constituição de políticas públicas estruturantes para a juventude brasileira e que essas se coadunem à prática social dos jovens como forma de se expressarem no mundo social, garantindo-lhes o direito ao trabalho como forma ontocriativa da existência (SAVIANI, 1994). 
Evangelista (2007) enfatiza em seus estudos que a vida dos jovens no contexto histórico-social ao longo dos séculos no nosso país tem sido marcada por rótulos originários de ideias estereotipadas introduzidas por agentes das políticas públicas e órgãos do Judiciário. Essa percepção é que nos impulsiona a compreender o movimento histórico que conduziu a instituição das Leis que garantem à educação e o trabalho para os jovens no país. Isso decorre da compreensão sociológica que informa que o desconhecimento do contexto e do desenvolvimento humano criaram expressões para representar os jovens, e, que essas, muitas vezes, obliteram a compreensão de que eles são sujeitos de direito. Evangelista diz ainda que, a Igreja Católica contribuiu com esse olhar para os jovens através das Santas Casas de Misericórdia, que se propunham a assistir meninos pobres, vadios, desvalidos e delinquentes. Esse autor também diz que o Código de Menores, de 1929, já destacava o problema do menor a partir da correção. O objetivo era "educar e disciplinar física, moral e civicamente o menor, visto como produto de pais vadios, pobres, irresponsáveis, ou resultante da orfandade." (2007, p. 10).

Os problemas dos jovens eram assim delegados à orfandade e à irresponsabilidade das familias pobres, desresponsabilizando-se, dessa forma, o Estado como responsável e condutor de políticas. Na segunda metade do século XX, durante o golpe civil/militar, de 1964, com a criação da Fundação Nacional do Bem-Estar do Menor (FUNABEM), identificou-se um processo de ampliação da presença estatal na formação da política social que caracterizou o período autoritário pós-1964, quando os interesses das comunidades foram excluídos dos processos decisórios e submetidos a um controle sistemático. Inspirado nos principios da doutrina de segurança nacional, preconizada pela Escola Superior de Guerra (ESG). (EVANGELISTA, 2007, p. 10). Nesse momento, a educação profissional passou a ser compulsória ao $2^{\circ}$ Grau (GERMANO, 1995). Em 1971, a Lei $n^{\circ} 5.692 / 71$ - Lei da Reforma de Ensino de $1^{\circ}$ e $2^{\circ}$ Graus - estruturou o ensino em $1^{\circ}$ e $2^{\circ}$ Graus, unificando as quatro séries do antigo ensino primário às quatro séries do ensino ginasial, consolidando $01^{\circ}$ Grau de oito anos de duração. $\mathrm{Na}$ prática, em consonância com Francisco Filho (2001, p. 118), não funcionou, pois 
"os professores permaneciam separados dividindo até mesmo a sala dos professores [...] não havia integração". No que concerne ao $2^{\circ}$ Grau, a referida lei estabelecia a obrigatoriedade da formação profissional. No entanto, baseado nos ensinamentos do mencionado autor observa-se que:

As escolas públicas não tinham as condições mínimas para promover tal profissionalização, faltava pessoal especializado, condições materiais e físicas. As escolas particulares, acostumadas na preparação da elite para as grandes universidades criaram um sistema para burlar a lei; constava nos seus currículos e programas a base profissional exigida, mas na prática trabalhavam os conteúdos à maneira antiga, atendendo às exigências dos grandes vestibulares. (2001, p. 118).

Pode-se interpretar que em todo o processo histórico da sociedade brasileira foi caracterizado ou delegado aos jovens pobres a responsabilidade pela violência, crime e vadiagem. Não se reconhecendo que esta situação é influenciada pela desigualdade social, pela exclusão da classe trabalhadora dos bens de cidadania, e por um sistema capitalista _ excludente e perverso _, legitimado pelo Estado capitalista brasileiro. Esse descaso com os jovens foi constituindo o que se denomina de violência juvenil e que assume diferentes feições: crime organizado, guerra do tráfico, arrastões, entre outras. Nesse contexto, os jovens passam a ser protagonistas e também vítimas da violência que vem sendo construida historicamente.

Abramovay e Feffermann (2007) afirmam que a relação de dominação no cotidiano desses jovens é marcada pela busca de um lugar no grupo, e muitas vezes, esse se encontra no tráfico de drogas, um lugar de destaque no contexto de vida dos jovens da periferia das grandes cidades. Reproduz-se assim, na cultura do tráfico de drogas, a relação de dominação a que são submetidos na sociedade ao mesmo tempo que mostra como a falta de educação e de trabalho ou de formação para o trabalho afeta negativamente a vida desses jovens.

A concepção sobre os jovens passa a ser associada a categorias como rebeldia, aventura e falta de interesse, condição que é acirrada quando alguns grupos juvenis expressam atitudes que podem ressignificar normas e padrões sociais vigentes. No Brasil há um crescente número de adolescentes em conflito 
com a lei como se pode identificar na pesquisa realizada por Evangelista (2007) que mostra o número de adolescentes infratores internados para cumprir medidas socioeducativas. Ainda de acordo com esse autor, em uma pesquisa divulgada pela Secretaria de Direitos Humanos (SEDH) o total de internos no sistema socioeducativo cresceu $28 \%$ entre 2002 e 2006, período investigado pelo autor. Isso de acordo com o autor significa que havia, no Brasil, nesse período 15.426 jovens cumprindo pena com algum tipo de restrição, dos quais 68\%, em regime de internação. A violência constitui, assim, nesta perspectiva, toda uma justificativa, que se institucionaliza nas ações de forma cristalizada.

Essa é uma problemática que tem relação direta ou indireta com a falta de uma educação profissional com qualidade referenciada para esses jovens. Essa afirmação corrobora resultados de estudos de que reconhecem que os valores e costumes de uma sociedade influenciam a construção de comportamentos violentos, deixando vulneráveis, as crianças e os jovens. Sabendo-se que esses afetam seu crescimento e desenvolvimento como seres humanos e sociais, portadores de sentido e, de significados construídos nas relações sociais. Vê-se, portanto, a necessidade de uma educação no país que reviva os sentidos do trabalho para a existência humana.

Pelas notas até aqui apresentadas justifica-se a adoção do estudo documental posto que o direito à profissionalização, garantido pela Lei Maior é regulamentado no Estatuto da Juventude. Esse deveria auxiliar a juventude na difícil tarefa de acesso à educação e prepará-la para o ingresso no mercado de trabalho ou no mundo do trabalho, como principio basilar da dignidade da pessoa humana.

A Lei n. ${ }^{\circ}$ 12.852/2013 promulgou o Estatuto da Juventude, determinando quais são os direitos dos jovens que devem ser garantidos e promovidos pelo Estado brasileiro, independente de quem esteja à frente da gestão dos poderes públicos. Essa Lei poderia servir de base para a formulação de políticas públicas para educação profissional, isso porque regulou onze direitos específicos: Direito à Diversidade e à Igualdade; Direito ao Desporto e ao Lazer; Direito à Comunicação e à Liberdade de Expressão; Direito à Cultura; Direito ao Território e 
à Mobilidade; Direito à Segurança Pública e ao Acesso à Justiça; Direito à Cidadania, à Participação Social e Política e à Representação Juvenil; Direito à Profissionalização, ao Trabalho e à Renda; Direito à Saúde; Direito à Educação; Direito à Sustentabilidade e ao Meio Ambiente. (BRASIL, 2013)6.

É necessário pontuar a importância por parte de uma agenda pública que assumia e incorpore as várias políticas governamentais de forma incondicional, de modo que permita e articule ações de enfrentamento às várias violações de direitos que afetam os jovens, pois como se percebe apenas a promulgação da lei não garante a sua efetividade.

Entende-se que os jovens como cidadãos têm direito à educação de qualidade, em todos os seus níveis, e que esta deve se adaptar às necessidades e especificidades da juventude, inclusive no período noturno. Direito este garantido pelo Estatuto da Juventude.

Ressalta-se também que o Estatuto já enfatiza a importância das políticas afirmativas e da expansão da educação superior nas instituições públicas, do financiamento e da assistência estudantil, das bolsas de estudos e do transporte escolar. Postula também, atender as necessidades dos jovens negros, do campo, indigenas e com deficiência, garantindo ainda a liberdade de organização dos estudantes e a sua participação efetiva para a gestão democrática das escolas e universidades.

Em 2012, os jovens na faixa etária de 15 a 17 anos, somavam 81,2\% frequentando a escola formal, mas destes apenas 54,4\% estavam no Ensino Médio o que já mostra uma enorme distorção idade-série, no caso idade-etapa da Educação Básica. O INEP destaca neste mesmo ano, com relação as matrículas da Educação Profissional vinculada ao Ensino Médio em torno de 16.3\%. Assim, das 1.362.200 matrículas, apenas 538.761 cursavam o Ensino Médio nas formas integrada e concomitante e os demais 823.429 cursavam a forma subsequente. Nesse sentido, enfatiza-se a diferença entre a necessidade de aumento da oferta da Educação Profissional Integrada ao Ensino Médio, pois a forma subsequente supera as duas formas articuladas em 284.668 matrículas.

${ }^{6}$ Disponivel em: http://www.planalto.gov.br/ccivil_03/_Ato2011-2014/2013/Lei/L12852.htm 
Isto demonstra que os jovens desejam uma formação profissional. (INEP, CENSO DA EDUCAÇÃO PROFISSIONAL 2010).

Compreende-se a Educação Profissional em sua perspectiva legal, como uma configuração de modalidade de ensino regida pela Lei de Diretrizes e Bases da Educação (LDB) nº 9.394/96, complementada pelo Decreto n².208, de 17 de abril de 1997 que foi reformado pelo Decreto $n^{\circ}$ 5.154, de 23 de julho de 2004 . Essa tem como objetivo principal a implementação de cursos que, voltados para o acesso ao mercado de trabalho, dirija-se tanto para estudantes quanto para profissionais que buscam ampliar suas qualificações para o trabalho.

Como se destacou a Educação Profissional no Brasil em seus indicadores mostra a dimensão da desigualdade social e política que afeta os jovens em idade escolar no Brasil. Porém é preciso enfatizar que a situação atual a qual os jovens são acometidos tem enraizamento histórico, fecundado pelos desmandos do sistema capitalista no país, amparados por um Estado cujos governos não têm se preocupado com a população para a qual se dirige esta Educação, isto é, os filhos da classe trabalhadora, ou como diz Moura (2012), os filhos daqueles que vivem do trabalho.

A educação profissional preceituada pelo Decreto $n^{\circ} 11.741$ de 2008 (BRASIL, 2016, sp)7, é definida nos seguintes artigos:

Art. 36-B. A educação profissional técnica de nível médio será desenvolvida nas seguintes formas:

I - articulada com o ensino médio;

II - subseqüente, em cursos destinados a quem já tenha concluído o ensino médio.

Parágrafo único. A educação profissional técnica de nivel médio deverá observar:

I - os objetivos e definições contidos nas diretrizes curriculares nacionais estabelecidas pelo Conselho Nacional de Educação; ensino:

II - as normas complementares dos respectivos sistemas de

III - as exigências de cada instituição de ensino, nos termos de seu projeto pedagógico.

Art. 36-C. A educação profissional técnica de nivel médio articulada, prevista no inciso I do caput do art. 36-B desta Lei, será desenvolvida de forma:

I - integrada, oferecida somente a quem já tenha concluído o ensino fundamental, sendo o curso planejado de modo a conduzir o

7 Disponivel em: http://www.planalto.gov.br/ccivil_03/leis/L9394.htm 
aluno à habilitação profissional técnica de nível médio, na mesma instituição de ensino, efetuando-se matrícula única para cada aluno;

II - concomitante, oferecida a quem ingresse no ensino médio ou já o esteja cursando, efetuando-se matrículas distintas para cada curso, e podendo ocorrer:

a) na mesma instituição de ensino, aproveitando-se as oportunidades educacionais disponiveis;

b) em instituições de ensino distintas, aproveitando-se as oportunidades educacionais disponiveis;

c) em instituições de ensino distintas, mediante convênios de intercomplementaridade, visando ao planejamento e ao desenvolvimento de projeto pedagógico unificado.

Art. 36-D. Os diplomas de cursos de educação profissional técnica de nivel médio, quando registrados, terão validade nacional e habilitarão ao prosseguimento de estudos na educação superior.

Percebe-se que a educação básica e a educação profissional, são um direito, e são requisitos fundamentais para todas as dimensões da vida. Assim, a compreensão de sua forma integrada traz uma dinâmica coerente com o que Frigotto (2001) e Moura (2008) enfatizam, qual seja, a formação integrando a escola de educação básica com a profissional, possibilitando construir nos alunos uma consciência crítica, um conhecimento global do mundo do trabalho, bem como de cidadania e de democracia.

Observa-se, no entanto, que a educação profissional no Brasil vem se ampliando desde os anos de 2007 em particular na forma subsequente. Assim no Anuário Brasileiro da Educação Básica $2014^{8}$ do total de 1.362, 200 alunos matriculados no ensino médio; 17,65\%, 240.226 são concomitante; 21,91\% , 298.545 são integrada e 60,44\%, 823.429 são do subsequente.

Oliveira (2012) destaca que a Educação Profissional democrática e emancipatória, é um elemento essencial à formação dos jovens e adultos que integram os processos educacionais no Ensino Médio e na Educação Profissional. Ainda de acordo com a autora:

O contexto atual, marcado pela continuidade no governo federal das forças políticas que se dizem comprometidas com um projeto societárioincludente, torna possivel pensar a elaboração e a execução de uma modelo de formação profissional cujo princípio político-pedagógico seja a formação de sujeitos capazes de efetivar práticas sociais direcionadas à construção de uma

8 Disponivel em: http://www.moderna.com.br/lumis/portal/file/fileDownload.jsp?fileld=8A8A8A824614522A01462512381317 E1 
sociedade mais igualitária; neste novo contexto, a educação profissional há de ser muito mais que a formação para uma atividade especifica no local de trabalho. Não pode se resumir apenas ao desenvolvimento de competências, como tanto defende os advogados do capital; muito menos pode ser uma ação compensatória e manipuladora de mentalidades. (OLIVEIRA, 2012, p. 101).

Nesse sentido, pode-se compreender que a autora defende a relevância da oferta da Educação Profissional articulada com as mudanças presentes no mundo do trabalho. Seria, logo, uma proposta de formação que vise atuar no sentido de transformação da realidade e inclusão dos que estão excluídos do direito à produção material e cultural, o que possibilita a oportunidade de se atingir expectativas reais de exercício do direito à cidadania. (OLIVEIRA, 2012).

Apreende-se que Educação representa tudo aquilo que pode ser feito para desenvolver o ser humano e, nesse sentido, representa a instrução e o desenvolvimento de competências e habilidades. Logo, o processo educacional tem um significado imprescindivel para o desenvolvimento do ser humano, pois permite que o homem alcance avanços significativos, no sentido da garantia de um futuro melhor. Partindo desta compreensão pode-se dizer que a educação é fundamental para vida em sociedade. Dessa forma, a percepção de Silva (2000) quando enfatiza o artigo 205 da Constituição Federal (BRASIL, 2007) mostra que essa dispõe a educação como um direito e cabe ao Estado e a família promovêla de modo que vise o pleno desenvolvimento da pessoa, seu preparo para o exercício da cidadania e sua qualificação para o trabalho.

A educação é um direito fundamental de natureza social, principalmente quando se compreende que para os indivíduos que se configuram como cidadãos em uma sociedade capitalista, o trabalho é a fonte de subsistência e garantia para a satisfação de suas necessidades. Dessa forma, a formação e qualificação para o trabalho pode se configurar em um problema social, por essa razão pode ser exigido do Estado ações que visem a sua satisfação, a sua garantia por meio de políticas públicas.

Por conseguinte, a pesquisa procura direcionar o estudo das políticas públicas de educação no Brasil no contexto do direito social e de 
responsabilidades estatais pela via de instrumentos da ação pública federativa, e de políticas de abrangência nacional. $O$ eixo da análise é o processo de democratização da educação, impulsionado pelo alargamento dos direitos à educação e da ação do Estado. De tal modo, as normas educacionais federativas comportam uma série de responsabilidades estatais na educação tanto no sentido de garantias como de efetivação do direito à educação e ao trabalho de forma articulada.

Assim para Frigotto (2001), o projeto do governo federal desde a organização ao conteúdo da (LDB) que regulamenta a Educação Profissional subordina-se as ideias do mercado e do capital, bem como, de um modelo excludente, concentrador de renda e predatório. Para tanto, chama a atenção para um projeto de Educação Profissional que se centre numa perspectiva emancipadora, a qual define em 5 pontos importantes:

1) No espaço ético-político a necessidade da construção contra hegemônica, na qual seus valores se concentrem na democracia efetiva, na igualdade e solidariedade entre os seres humanos;

2) No campo educativo centrar na ideia de uma educação omnilateral, tecnológica ou politécnica formadora de sujeitos autônomos e protagonistas de cidadania ativa e articulado com um projeto de Estado que vise um desenvolvimento sustentável;

3) A necessidade de uma formação técnico-profissional articulada a um projeto de desenvolvimento sustentável, e que essa seja vinculada a educação básica e a dimensão ético-política de formação dos sujeitos;

4) Que a educação profissional seja inscrita num projeto alternativo de desenvolvimento humano, social, político, cultural e econômico, no qual coloque o ser humano no centro e não o mercado.

5) A sociedade e a educação geral e profissional devem demandar de um processo que articule organicamente as relações sociais de produção e as relações políticas, culturais e educativas. (FRIGOTTO, 2001). 
Seguindo esse pensamento Frigotto (2001) defende uma educação que possibilite a mudança social. Mas, para isso é necessário que a educação seja apreendida na sua dimensão ontológica e histórica, de modo que permita a formação de um sujeito autônomo e crítico de sua realidade, social, econômica, política e cultural. Isto é, um ser que possa transformar sua realidade para uma sociedade mais justa e igualitária.

Nessa perspectiva, Moura (2008) destaca que as instituições de Educação Profissional e Tecnológica (EPT) enfrentam diversos desafios para cumprir a função que lhes demanda a sociedade. Defende que é necessário aproximar mais a ação de cada instituição de EPT do seu entorno para que possam penetrar mais na realidade social, econômica e laboral visando assim, contribuir para a sua transformação. Ainda de acordo com o autor é necessário estabelecer um diálogo social, que envolva as instituições e as áreas de conhecimento como a sociologia, a educação, a psicologia, a economia, e a organização empresarial, bem como, sindicatos e sociedade civil. Nessa perspectiva do diálogo contribuiriam essas instituições, compreendendo de forma mais profunda a realidade socioeconômica. Assim, poderiam atender às demandas e também, potencializar processos voltados para transformação da realidade socioeconômica e cultural garantindo aos jovens ali matriculados seus direitos constitucionais.

Moura e Lima Filho (2016, p. 06), conforme Tabela 1 abaixo mapearam a matrícula no ensino médio e na educação profissional técnica em nível médio no Brasil com dados do Censo Escolar de 2013. 
TABELA 1 - Matrícula no ensino médio e na educação profissional técnica de nível médio no Brasil por dependência administrativa2013

\begin{tabular}{|c|c|c|c|c|c|c|c|}
\hline & \multicolumn{5}{|c|}{$\begin{array}{c}\text { EM } \\
\text { (Regular) }\end{array}$} & \multicolumn{1}{c|}{$\begin{array}{c}\text { EM na } \\
\text { Modalida } \\
\text { Dependência } \\
\text { Administrativa EJA }\end{array}$} & TOTAL \\
\cline { 2 - 9 } & Propedêutico ${ }^{10}$ & $\begin{array}{l}\text { Normal/ } \\
\text { Magistério }\end{array}$ & Integrado & $\begin{array}{l}\text { Subtotal } \\
\text { regular }\end{array}$ & & \\
\hline Brasil & 5.525 .747 & 2.328 .460 & 120.218 & 338.390 & 8.312 .815 & 1.324 .878 & 9.637 .69 \\
\hline Federal & 20.191 & 256 & - & 117.747 & 138.194 & 13.606 & 151.800 \\
\hline Estadual & 4.467 .561 & 2.287 .103 & 108.652 & 183.637 & 7.046 .95 & 1.168 .925 & 8.215 .878 \\
\hline Municipa & 23.332 & 21.880 & 6.679 & 10.738 & 62.629 & 40.328 & 102.957 \\
\hline Privada & 1.014 .663 & 19.221 & 4.887 & 26.268 & 1.065 .03 & 102.019 & 1.167 .058 \\
\hline
\end{tabular}

Fonte: Moura e Lima Filho, 2016, p, 06.

Ao analisar os dados da Tabela 1, observa-se que o Ensino Médio é ofertado especialmente na rede estadual de ensino, totalizando $88,2 \% \mathrm{em}$ toda a rede pública. Já a educação profissional técnica em nivel médio corresponde a apenas $6.58 \%$ de toda a oferta do Ensino Médio.

Deste modo, dentro do quadro nacional esta oferta ainda é incipiente, especialmente, se imaginarmos a população nacional de mais de 200 milhões de habitantes (IBGE, 2016), que necessitam de mínimas condições de educação para ingresso de forma eficaz e eficiente no mercado de trabalho. Esses por si já são indícios de que a Educação Profissional atendia minimamente à demanda a qual se destina.

Tabela 2 - Evolução do número de matriculas na Educação Profissional - Brasil - 2008/2014

\begin{tabular}{c|c|c|c|c|c}
\hline \multirow{2}{*}{ NÚMERO DE MATRÍCULAS } & \multicolumn{5}{|c}{ ANO } \\
\cline { 2 - 6 } & $\mathbf{2 0 0 8}$ & $\mathbf{2 0 1 0}$ & $\mathbf{2 0 1 2}$ & $\mathbf{2 0 1 4}$ & $\begin{array}{c}\Delta \% \\
\mathbf{2 0 0 8 / 2 0 1 4}\end{array}$ \\
\hline $\begin{array}{c}\text { EDUC. PROF. (CONCOMITANTE } \\
\text { E SUBSEQUNTE) }\end{array}$ & 795.459 & 924.670 & 1.063 .655 & 1.374 .569 & 72,8 \\
\hline
\end{tabular}

Fonte: MEC/Inep/Deed (adaptada)

No ano de 2015, o IBGE (2013) tinha uma estimativa de que a população jovem e adulta (dos 15 aos 59 anos) totaliza um total de mais de 130 milhões. 0

Inclui matriculas na EJA presencial médio, semi-presencial médio e integrada à educação profissional no ensino médio.

${ }^{10} \mathrm{Na}$ verdade, para a maioria dos sujeitos do ensino médio, especialmente, os das classes trabalhadoras populares que estudam em escolas estaduais e municipais, a oferta é apenas pretensamente propedêutica, posto que, na prática, não prepara os estudantes efetivamente para a fase de estudos posterior, o ensino superior. 
Ministério da Educação, segundo a Tabela 2 acima, destaca que há uma oferta de educação profissional para mais de 1 milhão e 300 mil pessoas, o que equivale a média de $1 \%$ da população jovem e adulta.

No que se refere às instituições de ensino, conforme Tabela 3, o levantamento estatístico do Ministério da Educação a partir do Censo Escolar de 2014, demonstra que há 5.325 escolas que ofertam a educação profissional técnica, que atendem a mais de um milhão e 370 mil educandos.

Tabela 3 - Evolução do número de matrículas na Educação Profissional por dependência administrativa - Brasil - 2008/2014

\begin{tabular}{c|c|c|c|c|c}
\hline \multirow{2}{*}{ ANO } & \multicolumn{5}{|c}{ MATRÍCULAS NA EDUCAÇÃO PROFISSIONAL POR DEPENDÉNCIA } \\
& \multicolumn{5}{|c}{ ADMINISTRATIVA } \\
\cline { 2 - 6 } & TOTAL & FEDERAL & ESTADUAL & MUNICIPAL & PRIVADA \\
\hline $\mathbf{2 0 0 8}$ & 942.917 & 132.732 & 322.362 & 36.120 & 451.703 \\
\hline $\mathbf{2 0 1 0}$ & 1.178 .540 & 179.433 & 418.157 & 32.265 & 548.685 \\
\hline $\mathbf{2 0 1 2}$ & 1.398 .193 & 224.892 & 505.714 & 31.056 & 636.531 \\
\hline $\mathbf{2 0 1 4}$ & 1.784 .403 & 249.604 & 536.678 & 40.927 & 957.194 \\
\hline $\mathbf{\Delta \%}$ & 89,2 & 88,1 & 66.5 & 13.3 & 111.9 \\
$\mathbf{2 0 0 8 / 2 0 1 4}$ & & & & & \\
\hline
\end{tabular}

Fonte: MEC/Inep

Ao destacar a evolução do número de matrículas na educação profissional no contexto brasileiro, a partir dos dados da Tabela 3, observa-se um aumento significativo de 89,2\%. Contudo, ao se analisar a Projeção do Censo Populacional de 2013 percebe-se a necessidade de um aumento ainda maior na oferta desta modalidade de ensino para a promoção do direito à educação e ao trabalho de modo a garantir o que prevê a legislação pátria e que é desejado no meio social.

Esses dados dão o tom da necessidade de confrontar na pesquisa informações de indicadores oficiais para sedimentar a análise argumentativa da pesquisa de forma contextualizada com a realidade.

Para compreender o direcionamento do estudo em questão é imprescindivel apontar o conceito que apoia nossos estudos sobre política pública. Sendo esse um conceito complexo e amplo, respalda-se na concepção de Muller e Surel (2012, p. 11), que a entende como programas de ação pública, isto é "[...] dispositivos político-administrativos coordenados em princípio em torno 
de objetivos explícitos". Assim, compreendida como espaços de construção de sentido, pois são um elemento da participação política. Os autores nos permitem "vincular as políticas, no sentido de policies, às dinâmicas e aos atores que caracterizam a politica (politics) e aos processos e às interações que concorrem para a formação e a evolução da polity" (MULLER e SUREL, 2002, p. 30). De modo que se procura agir para transformar uma situação, problema ou demanda.

Portanto, em consonância com esse pensamento Arretche (2003) destaca que analisar a política no sentido do "Estado em ação" objetiva apreender os programas governamentais, suas condições de emergência, mecanismos de operação e prováveis impactos sobre a ordem social e econômica (FARENZENA e LUCE, 2014).

E para destacar nosso estudo no cenário brasileiro é necessário fazer um breve histórico da configuração da construção da política pública no Brasil. Nossos estudos se baseiam no pensamento de Trevisan e Belen (2008) que enfatizam não apenas como ocorreu bem como, a ampliação dos estudos sobre a construção histórica da agenda de políticas públicas no Brasil. Assim os autores apontam baseados em Melo (1998), que a análise das políticas públicas conheceu seu apogeu na década de 1980, impulsionada pela transição democrática. Este autor ainda destaca três os motivos da expansão. O primeiro ocorreu pelo deslocamento na agenda pública, estruturando-se por questões relativas ao modelo de desenvolvimento brasileiro, e se limitava aos impactos redistributivos da ação governamental e ao tipo de racionalidade que conduzia o projeto de modernização conservadora do regime ditatorial. O segundo, com o fim do período autoritário, percebeu-se que os obstáculos à consecução de politicas sociais efetivas continuaram existindo, o que possibilitou 0 fortalecimento dos estudos sobre políticas. Essa situação levou a um maior interesse sobre as condições de efetividade da ação pública. E por fim o terceiro, a ideia de reforma do Estado e do aparelho de Estado se tornou o princípio organizador da agenda pública dos anos 1980-1990, o que provocou uma proliferação de estudos sobre políticas públicas. 
Os estudos sobre política pública são importantes, pois a compreensão do sucesso e do fracasso das políticas públicas são fundamentais para o melhoramento do desempenho da administração pública, o que demanda apreender o "Estado em ação". (TREVISAN e BELEN, 2008). Seguindo o pensamento dos autores ancorados nas ideias de Frey (2000) destaca-se que o agir público pode ser dividido em fases parciais do processo político administrativo para a solução de problemas. E aponta que as propostas de análise se configuram no que os autores chamaram de ciclo político que se dividem em fases: a formulação, a implementação e o controle dos impactos das políticas. Assim, o ciclo de políticas públicas é um esquema de visualização e interpretação que organiza a vida de uma política pública em fases sequenciais e interdependentes que se configuram de acordo com Secchi (2011) em 6 etapas quais sejam:

a) Identificação do problema: um problema é a discrepância entre o status quo e uma situação ideal possivel;

b) A formação de agenda: é um conjunto de problemas ou temas entendidos como relevantes, que se divide em agenda política - conjunto de problemas ou temas que a comunidade política percebe como merecedor de intervenção pública, e agenda formal - também conhecida como agenda institucional, é aquela que elenca os problemas ou temas que o poder público já decidiu enfrentar;

c) Formulação de alternativas: a formulação de soluções passa pelo estabelecimento de objetivos e estratégias, e este pode ser alcançado de várias formas, por diversos caminhos;

d) A tomada de decisão: é o momento em que os interesses dos atores são equacionados e as intenções (objetivos e métodos) de enfrentamento de um problema público são explicitadas

e) A implementação da política pública: esta fase é aquela em que regras, rotinas e processos sociais são convertidos de intenções em ações. E neste momento se pode visualizar os obstáculos e as falhas que 
costumam acometer a política pública, bem como os erros anteriores à tomada de decisão, a fim de detectar problemas mal formulados, objetivos mal traçados, otimismos exagerados; e

f) A avaliação de políticas e da correção de ação (evaluation), na qual se apreciam os programas já implementados no que diz respeito aos seus impactos efetivos. (SECCHI, 2011)

Seguindo a compreensão desse autor a avaliação é importante como ferramenta de investigação dos déficits, do impacto e dos efeitos colaterais indesejados de uma política pública, assim, a avaliação se define como um processo de julgamentos sobre a validade das propostas para a ação pública. Para tanto, estabelece 3 elementos de uma avaliação (critérios; indicadores e padrões) e critérios usados para avaliar, tais como: economicidade; eficiência econômica; eficiência administrativa; eficácia e equidade.

Corroborando esse pensamento "a fase da avaliação é imprescindivel para o desenvolvimento e a adaptação contínua das formas e instrumentos de ação pública" (FREY, 2000, apud TREVISAN e BELEN, 2008, p. 531). Desse modo, os autores enfatizam que é possivel perceber caso os objetivos do programa tenham sido atendidos, o ciclo político, que poderá ser suspenso ou finalizado, e caso não ocorra se iniciará uma nova fase de percepção e definição de problemas.

Nessa perspectiva acredita-se que avaliar as políticas sobre educação profissional nos permitiria compreender de uma forma mais profunda a realidade da efetivação dessas políticas na formação dos jovens como sujeitos de direitos e cidadãos críticos de sua realidade, se atendem as demandas e também, potencializar processos voltados para transformação da realidade socioeconômica e cultural.

\section{Objetivos}

Desenvolver um estudo exploratório acerca da juventude brasileira em articulação com a Educação Profissional com vistas a compreender como o 
Estado brasileiro atende o direito à educação e ao trabalho para esses sujeitos. 0 estudo se desenvolve a partir de uma perspectiva articuladora dos direitos à educação e ao trabalho, pela via da Educação Profissional, tendo em vista a relação indissociável destas premissas constitucionais.

\section{Metodologia}

Enfatiza-se que as estratégias metodológicas de uma pesquisa são caminhos que guiam o pesquisador no percurso da pesquisa. Este estudo de cunho bibliográfico e documental tem sua empiria delineada nos indicadores oficiais sobre Educação Profissional como forma de argumentos para desvelar o objeto de estudos no contexto das políticas públicas educacionais. Especificamente, nas matrículas da Educação Profissional vinculadas ao Ensino Médio e à forma subsequente, bem como, nas implicações desta para a ampliação das vagas na forma integrada.

De acordo com Minayo e Sanches (1993), o conhecimento científico sempre transcorre como a busca de articulações entre teoria e realidade, tendo como fio condutor o método, com a função fundamental de articular e fundamentar esses conhecimentos de maneira a proporcionar um caminho claro de investigação.

Assim sendo, pretende-se para o desenvolvimento desta pesquisa inicialmente fazer uma ampla pesquisa bibliográfica sobre a temática para a construção do referencial teórico embasado em autores como Frigotto e Ciavatta(2009), que refletem sobre a relação entre educação, formação profissional e desenvolvimento nas sociedades capitalistas; e Moura (2008) que enfatiza a formação humana no contexto da Educação Profissional integrada ao Ensino Médio. Assim, a pesquisa bibliográfica contribuirá para a parte teórica deste estudo, no qual se busca discutir sobre as políticas de Educação Profissional e suas relações nem sempre explícitas coma garantia dessa como direito dos jovens. 
Concomitante à pesquisa bibliográfica será realizada a pesquisa documental, que de acordo com Marconi e Lakatos (2012, p. 51), "constituem geralmente a fonte mais fidedigna de dados. Podem dizer respeito a atos individuais ou, ao contrário, atos de vida pública, de alcance municipal, estadual ou nacional". Este tipo foi escolhido por trazer substratos para a análise das políticas em discussão.

Os documentos selecionados para a pesquisa referem-se aos mecanismos de regulação produzidos nas instâncias centrais do Estado, tais como: Leis, decretos e portarias que orientam as formas de controle e coordenação pelas autoridades públicas sobre o sistema de ensino e as políticas educacionais, esses já receberam tratamento institucional e jurídico-legal. A Constituição Federal (1988) os documentos orientadores das políticas e programas de Educação Profissional principalmente os elencados no Decreto $n^{\circ} 11.741 / 2008$ que regulamenta as formas de oferta da Educação Profissional no Brasil e as mais importantes normas legais concernentes à educação, à profissionalização e ao trabalho juvenil serão analisados, observando-se a proteção legal integral e as políticas públicas, além de avaliar até que ponto estes direitos tem sido implementados no país. Entende-se que educação e trabalho são temas juridicamente complexos, notadamente pelo volume de normas que disciplinam cada um desses direitos.

A afirmação anterior pode ser observada na Lei de Diretrizes e Bases da Educação (LDB); no instituto da Aprendizagem, previstos na Consolidação das Leis do Trabalho (CLT) e também assegurados pelo Estatuto da Criança e do Adolescente (ECA); além dos novos fomentos de políticas públicas direcionadas à profissionalização que necessitem de análise caso apareçam como necessárias durante a pesquisa. Por essa razão, será feito também um levantamento da produção do conhecimento em torno do tema em bases de dados acadêmicos oficiais a exemplo do Portal da Coordenação de Aperfeiçoamento de Pessoal de Nivel Superior (CAPES).

Ainda se fará levantamento dos indicadores da Educação Profissional no Brasil de 2008 a 2016 nos Censos Escolares de 2008 a 2016, disponibilizados no 
site do Instituto Nacional de Estudos e Pesquisas Educacionais Anísio Teixeira (INEP), nos Relatórios anuais de análise dos indicadores de gestão (2008-2016). Assim como, se buscará dados sobre o perfil socioeconômico da população jovem no Brasil no Instituto Brasileiro de Geografia e Estatistica (IBGE) e Instituto de Pesquisa Econômica Aplicada (IPEA). Acredita-se que, da seleção e do cruzamento dos dados obtidos, numa leitura qualitativa, se possa fazer a análise sobre a formação dos jovens brasileiros para inserção no mundo do trabalho, observando-se a garantia de seus direitos ao trabalho, bem como os sobrantes nessa relação comparativa entre a população jovem e a oferta de Educação Profissional no Brasil.

Percebe-se que as políticas públicas não possuem uma centralidade quando o assunto é Educação Profissional, servindo-se, muitas vezes, de práticas imediatistas e assistencialistas, sem análise técnica e, nem mesmo de seus indicadores pela via do monitoramento e avaliação dessas. Por esse motivo, esses serão utilizados como forma de constituição de argumentações sólidas, considerando-se que esses podem de modo incisivo mostrar que os jovens pobres do Brasil sofrem com as barreiras de acesso à educação e ao trabalho. Servem, portanto, como substrato para o método de exposição a ser desenvolvido na produção desse estudo, baseado em indicadores cujas informações desses, derivadas sedimentarão a argumentação.

Como metodologia investigativa e expositiva tem-se a abordagem materialista-dialética no sentido de análise da realidade por meio de: pesquisa bibliográfica acerca dos fundamentos da Educação Profissional oferecida no Brasil; análise de instrumentos jurídicos/legais tais como, o texto Constitucional atual, o Estatuto da Criança e do Adolescente, a Lei de Diretrizes e Bases da Educação, as Consolidações das Leis do Trabalho e do Estatuto da Juventude. Busca-se, assim, evidenciar as principais politicas públicas voltadas à garantia dos direitos à educação e ao trabalho, bem como analisar os indicadores oficiais sobre educação profissional nas bases de dados do Estado brasileiro em domínio público. 
Trata-se, portanto, de um estudo quali-quantitativo de base legal com fundamentos histórico-críticos que se alicerçará em indicadores que mostrarão a garantia ou não da educação como preparação para o trabalho para os jovens no Brasil do século XXI.

\section{Resultados e impactos esperados}

Pretende-se com esse trabalho, analisar o contexto histórico, social e político ao qual se configurou o acesso da juventude a direitos fundamentais. Espera-se também, promover a realização de encontros para divulgação dos relatórios intercalares, bem como oferecer subsídios para a compreensão do fenômeno e fomentar a ampliação da discussão e da produção cientifica sobre a temática a efetivação da política pública de acesso à educação e em específico da Educação Profissional entre os anos de 2008 a 2016.

\section{Referências}

ABRAMOVAY, M.; FEFFERMANN, M. Juventude e sociabilidade vivendo uma cultura de violência. In: Sociologia Especial, SP, ano I, n.2, p. 46-55. 2007.

ANTUNES, R. Os Sentidos do Trabalho: ensaio sobre a afirmação e a negação do trabalho. São Paulo: BOITEMPO, 2000.

ARANHA, M. L. de A. História da educação e da pedagogia. 3. ed. rev. ampl. São Paulo: Moderna, 2006.

ARAUJO, R. M. de L.; RODRIGUES, D. S. Referência sobre práticas formativas em educação profissional. In: ARAUJO, R. M. de L.; RODRIGUES, D. S. (Org.). Filosofia da Práxis. Campinas, SP: Autores Associados, 2011.

BARROS, A. M. de. Curso de Direito do Trabalho. 4 ed. São Paulo, LTr, 2008, p. 5455 .

BELLUZZO, L.; VICTORINO, R.. A juventude nos caminhos da ação pública. São Paulo Perspec., São Paulo: vol. 18, n. 4, 2004. (pp. 8-19).

BOURDIEU, P. A "juventude" é apenas uma palavra! Questões de sociologia. Rio de Janeiro: Marco Zero, 1983. (pp. 112-121). 
BOMFIM, M. A América Latina: males de origem. Rio de Janeiro: Centro Edelstein de Pesquisas Sociais, 2008. 291 p. Disponivel em:

<http://static.scielo.org/scielobooks/zg8vf/pdf/bomfim-9788599662786.pdf>. Acesso em: 22 fev. 2013.

BONETI, L. W. Sociologia da educação. Curitiba: Camões, 2008, p.85.

BRASIL. Constituição da República Federativa do Brasil de 1988. Disponível em:<http://www.planalto.gov.br/ccivil_03/Constituicao/Constituiçao.htm>. Acesso em 11 de julho de 2016.

Consolidação das Leis do Trabalho. Disponivel em:<http://www.planalto.gov.br/ccivil_03/Decreto-Lei/Del5452.htm>. Acesso em 12 de julho de 2016.

Diretrizes e Bases da Educação Nacional. Disponivel em:<http://www.planalto.gov.br/ccivil_03/leis/L9394.htm>. Acesso em 12 de julho de 2016.

Estatuto da Criança e do Adolescente. Disponível em:

<http://www.planalto.gov.br/ccivil_03/Leis/L806g.htm>. Acesso em 12 de julho de 2016.

Estatuto da Juventude. Disponível

em:<http://Www.planalto.gov.br/CCIVIL_03/_Ato2011-

2014/2013/Lei/L12852.htm>. Acesso em 12 de julho de 2016.

Ministério da Educação. Lei nº 9.394, de 20 de dezembro de 1996

Estabelece as diretrizes e bases da educação nacional. Disponivel em:<http://www.planalto.gov.br /ccivil_03/leis/l9394.htm>. Acesso em: 10 out.2014.

Presidência da República. Decreto n 5.154, de 23 de julho de 2004 Regulamenta o $\S 2^{\circ}$ do art. 36 e os arts. 39 a 41 da Lei $n^{\circ}$ 9.394, de 20 de dezembro de 1996, que estabelece as diretrizes e bases da educação nacional. Brasilia, 2004.

Presidência da República. Decreto n. 2.208, de 17 de abril de 1997. Regulamenta o $\S 2^{\circ}$ do art. 36 e os artigos 39 a 42 da Lei federal $n^{\circ}$. 9.394/96. Brasilia, DF: 17 abr. 1997.

CANOTILHO, J.J. G. Direito constitucional e teoria da constituição. 4. ed. Coimbra: Almedina, 2000, p. 387.

CASTRO, J. A.; OLIVEIRA, M. G. de. Políticas Públicas e desenvolvimento. In_ Avaliação de Políticas Públicas. MADEIRA, L. M. (Org.). Porto Alegre: UFRGS/CEGOV, 2014. 
CIAVATTA, M. A Formação integrada: a escola e o trabalho como lugares de memória e de identidade. In: FRIGOTTO, G.; CIAVATTA, M.; RAMOS, M. Ensino Médio Integrado: concepções e contradições. São Paulo: Cortez, 2005.

CUSTÓDIO, A. V. C.; VERONESE, J. R. P. Trabalho infantil: a negação do ser criança e adolescente no Brasil. Florianópolis: OAB/SC, 2007, p. 242.

DALLEGRAVE NETO, J. A. Contrato de trabalho especial de aprendizagem. Revista de Direito do Trabalho. n. 128. São Paulo: RT, outubro-dezembro de 2007. p. 378

EVANGELISTA, D. de O. Sem eira, nem beira: adolescentes em conflito com a lei e as políticas públicas de atendimento. Revista Inter-legere; ano 1; $n^{\circ}$ 1; Jan/jul, 2007.

FARENZENA e LUCE, Políticas Públicas de Educação no Brasil: Reconfigurações

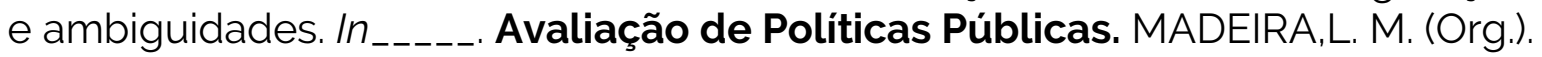
Porto Alegre: UFRGS/CEGOV, 2014.

FRANCISCO FILHO, G. A educação nos governos militares (1964-1985). A educaçãoe a transição democrática (1985-2001). In: A educação brasileira no contexto histórico. Campinas: Alínea, 2001 p. 113-155.

FREIRE, P. A Educação na cidade. São Paulo: Cortez, 1991.

FRIGOTTO, G. Educação, crise do trabalho assalariado e do desenvolvimento: Teorias em conflito. In: FRIGOTTO, G. (Org.). Educação e Crise do Trabalho: perspectiva de final de século. Petrópolis, RJ: Vozes, 1998.

FRIGOTTO, G. Juventude, Trabalho e Educação no Brasil: perplexidades, desafios e perspectivas. In: NOVAES, R. e VANUCHI, P. Juventude e sociedade: trabalho, educação, cultura e participação. São Paulo: Fundação Perseu Abramo, 2004.

FRIGOTTO, G. A relação da educação profissional e tecnológica com a universalização da educação básica. In: MOLL, Jaqueline et al . Educação Profissional e Tecnológica no Brasil Contemporâneo: desafios, tensões e possibilidades. Porto Alegre: Artmed, 2010.

GARCIA, G. F. B. Curso de Direito do Trabalho. 3. ed. São Paulo: Método, 2009. GERMANO, J. W. Estado militar e educação no Brasil. 5. ed. São Paulo: Cortez, 2011.

GIL, A. C. Como elaborar projetos de pesquisa. São Paulo: Atlas, 2009.

GILES, T. R. Quadros da História do processo educativo no Brasil. In: História da Educação. São Paulo: EPU, 1987. 
INSTITUTO NACIONAL DE ESTUDOS E PESQUISAS EDUCACIONAIS ANÍSIO Teixeira. Censo da Educação Profissional 2010. Brasília. Disponível em: http://download.inep.gov.br/download/censo/2010/divulgacao_censo2010_20 1210.pdf. Acesso em: julho de 2015.

INSTITUTO BRASILEIRO DE GEOGRAFIA E ESTATÍSTICA. População. Disponível em: <http://www.ibge.gov.br/apps/populacao/projecao/ >. Acesso em: 14 jan. 2016

INSTITUTO BRASILEIRO DE GEOGRAFIA E ESTATISTTICA. Projeção da população. Disponivel em:

<http://www.ibge.gov.br/home/estatistica/populacao/projecao_da_populacao / 2013/default_tab.shtm>. Disponivel em: 14 jan. 2016.

KUENZER, A. Z. A educação profissional nos anos 2000: a dimensão subordinada das políticas de inclusão. Educação e Sociedade, Campinas, vol. 27, n. 96 Especial, p. 877-910, out. 2006

MACHADO, L. MACHADO, J. Globalização capitalista e apropriação: implicações educacionais e ambientais. In: LUCENA, C. (Org.). Capitalismo, Estado e Educação. Campinas, SP: Alínea, 2008.

MARTINS FILHO, I. G. da S. Manual Esquemático de Direito e Processo do Trabalho. 15. ed. São Paulo, 2007, p. 3.

MARX, K. O Capital: crítica da economia política. Tradução por Regis Barbosa e Flávio R. Kothe. São Paulo: Abril Cultural, 1985, p. 50

MARX, K. O capital (crítica da economia política). Livro 1 v. 1. Tradução de Regis Barbosa e Flávio R. Kothe. São Paulo: Editora Nova Cultural Ltda, 1996, 473p.

MINISTÉRIO DA EDUCAÇÃO. Dados Censo 2015. Disponível em: <http://portal.mec.gov.br/index.php?option=com_docman\&view=download\&alia $\mathrm{S}=17044-\mathrm{da}$ dos-censo-2015-11-02-materia\&Itemid=30192>. Aceso em: $14 \mathrm{fev}$. 2015.

MONTALVÃO, S. A LDB de 1961: apontamentos para uma história política da educação. In: Revista Mosaico. Rio de Janeiro, PPHPBC-FGV, ed. n. 3, ano II, 2010. Disponivel em: <http://cpdoc.fgv.br/mosaico/>. Acesso em: 14 jan. 2016.

MOURA, D. H. Políticas públicas para a educação profissional técnica de nível médio nos anos 1990 e 2000: limites e possibilidades. In: OLIVEIRA, Ramon de (Org.). Jovens, Ensino Médio e Educação profissional: políticas públicas em debate. 1. ed. Campinas: Papirus, 2012.

MOURA, D. H. Educação Básica e Educação Profissional e Tecnológica: dualidade histórica e perspectivas de integração. In: Holos, Ano 23, Vol. 2 - 2007. Disponivel 
em: <http://www2.ifrn.edu.br/ojs/index.php/holos/article/viewFile/11/110>. Acesso em: 14 jan. 2016.

MOURA, H. D. A formação de docentes para a educação profissional e tecnológica. Revista Brasileira da educação profissional e tecnológica. Brasilia: MEC, SETEC, v. 1, n. 1, jun., 2008.

MOURA, H. D.; LIMA FILHO, D. L. Os diferentes e desiguais ensinos médios no Brasil: o que fazem os que trabalham durante esta etapa educacional.XXIII Encontro de Pesquisa Educacional do Norte Nordeste. EPENN, Teresina,Brasil Anais [Recurso Eletrônico]/ Universidade Federal do Piaui. Centro de Educação. Programa de Pós-graduação em Educação. Teresina, PI, 2016.

MULLER, P.; SUREL, Y. A análise das políticas públicas. Pelotas: Educat, 2002. NASCIMENTO, A. M. Iniciação do direito do trabalho. 31. ed. São Paulo, LTr, 2005. p. 47.

OLIVEIRA, R. Empregabilidade. In: Dicionário da Educação Profissional em Saúde / Isabel Brasil Pereira e Júlio César França Lima. 2. ed. Rio de Janeiro: EPSJV, 2008.

OLIVEIRA, O. de. Trabalho e profissionalização do adolescente. São Paulo: LTr, 2009 .

OLIVEIRA, R. de. Por uma educação profissional democrática e emancipatória. In: OLIVEIRA, R. de. (Org.) Jovens, Ensino Médio e Educação Profissional: políticas públicas em debate. Campinas: Papirus, 2012.

RAMOS, M. Possibilidades e desafios na organização do curriculo integrado. In: FRIGOTTO, G.; CIAVATTA, M.; RAMOS, M. Ensino Médio Integrado: concepções e contradições. São Paulo: Cortez, 2005.

RAMPAZZO, L. Metodologia Científica. São Paulo: Loyola, 2005.

SANTOS, B. de S. (Org.). A Globalização e as Ciências Sociais. São Paulo: Cortez, 2002.

SANTOS, S. C. M. Nas veredas por reconhecimento social: o papel da educação na desconstrução da inferioridade dos sujeitos do campo. Tese Doutorado.

Universidade Federal do Rio Grande do Norte. Centro de Ciências Humanas, Letras e Artes. Programa de Pós Graduação em Ciências Sociais, 2012.

SAVIANI, D. O trabalho como principio educativo frente às novas tecnologias. In: FERRETI, C. et al. (Org.) Novas Tecnologias, Trabalho e Educação: um debate multidisciplinar. Petrópolis: Vozes, 1994. 
SAVIANI, D. Trabalho e educação: fundamentos ontológicos e históricos. Revista Brasileira de Educação, v. 12 n. 34 jan./abr. 2007. Disponivel em:

http://www.scielo.br/pdf/rbedu/v12n34/a12v1234.pdf. Acesso em: novembro de 2015 .

SAVIANI, D. Vicissitudes e perspectivas do direito à educação no Brasil: abordagem histórica e situação atual. Educação e Sociedade. Campinas, v. 34, n. 124, p. 743-760, jul.-set. 2013. Disponivel em:

<http://www.scielo.br/pdf/es/v34n124/06.pdf>. Acesso em: 14 jan. 2016

SARLET, I. W. A eficácia dos direitos fundamentais. 8. ed. Porto Alegre: Livraria do Advogado, 2010, p. 26.

SECCHI, L. Políticas Públicas: Conceitos, Esquemas de Análise, Casos Práticos. São Paulo: Cengage Learning, 2011.

SILVA, J. A. da S. Comentário Contextual à Constituição. 3. ed. São Paulo: Malheiros, 2007.

SILVA, J. A. da. Curso de Direito Constitucional Positivo. 34. ed. rev. atual. São Paulo: Malheiros, 2011.

SILVA, L. L. S.; AZEVEDO, M. A. Reforma educativa a partir dos anos 1990: implementação na América Latina e Caribe e particularidades brasileiras. Holos, v. 2 , p. $250-260$, mai. 2

TAKEUTI, N. M. No outro lado do espelho: a fratura social e as pulsões juvenis. Rio de janeiro: Relume Dumará; Natal: Universidade Federal do Rio Grande do Norte, 2002.

TREVISAN, A. P.; BELEN, H. M. V. Avaliação de políticas públicas: uma revisão teórica de um campo em construção. Revista de Administração Pública, Rio de Janeiro 42(3):529-50, maio/jun, 2008.

VERONESE, J. R. P; SILVEIRA, M. Estatuto da Criança e do Adolescente Comentado. São Paulo: Conceito Editorial, 2011. 